\title{
Review of Leading Change in Academic
}

\section{Libraries}

Michelle Colquitt

Georgia Gwinnett College

Abstract: Review of Boff, C., \& Cardwell, C. (2020). Leading change in academic libraries. Chicago, IL: Association of College \& Research Libraries.

Keywords: change, academic library, ACRL monograph, Kotter model

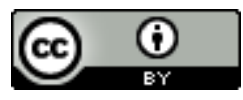

This is an Open Access article distributed under the terms of the Creative Commons Attribution 4.0 International License (http://creativecommons.org/licenses/by/4.0), which permits unrestricted use, distribution, and reproduction in any medium, provided the original work is properly cited. 
Conceptualizing and enacting change are difficult charges in academic libraries. In Leading Change in Academic Libraries Dr. Colleen Boff and Dean Catherine Cardwell discuss various case studies of change through the lens of Dr. John P. Kotter's initial article (1996) and subsequent book (2012) which outlines an eight-step process to organizational change. Kotter outlines the eight steps as "1. Establishing a Sense of Urgency, 2. Forming a Powerful Guiding Coalition, 3. Creating a Vision, 4. Communicating the Vision, 5. Empowering Others to Act on the Vision, 6. Planning and Creating Short Term Wins, 7. Consolidating Improvements and Producing Still More Change, and 8. Institutionalizing New Approaches." Viewing change within Kotter's lens, libraries can capably manage institutional changes holistically.

As a relative newbie to the library world, I was not aware of how change could be accomplished in this arena. This text energized me about the prospect of change in the academic library world in general and upon completion I believe I can effectively actuate change in my library. This text is the perfect marriage of business theory and library science, which is so beneficial to me as the new liaison to the School of Business.

This text presents case studies and analyses from four-year college or university libraries in the specific areas of Strategic Planning, Reorganization, Culture Change, New Roles, and Technological Change. Boff and Cardwell (2020) relate that this text is "...not intended to be a critique of the institutions; rather it is intended to use Kotter's model as a tool to help others learn about best practices, common obstacles, and more" (p. xvi). Also established is the fact that, while difficult, enacting change is possible. Change as presented in this text is not as linear or tidy as the Kotter model, however, it has been enacted at each institution. Boff and Cardwell provide an excellent, indepth outline of the entire process of calling for proposals and the guiding questions of the ACRL Monographs Project.

\section{Part 1. Strategic Planning}

Covered in this section are case studies from Miami $(\mathrm{OH})$ University, Montana State University, the University of Tennessee, and Wesleyan University. With the exception of Wesleyan, these 
universities are all larger doctoral granting institutions. Working with a consulting firm, Miami undertook a strategic planning process to evaluate best practices regarding the use of space, staff organization, and space renovation.

Montana State University also worked with a consultant to implement the Balanced Scorecard framework, a business framework that “...helps employees align their day-to-day work with a comprehensive strategy, and [the BSC] helps administrators monitor and measure progress toward implementation of the plan" (Johnson, et. al p. 14). This article reflected on Kotter's model in terms of the BSC.

The University of Tennessee completed this process in-house, creating a StAR team (Strategic Achievement Review) to communicate and help enact change. Brannen, Mays, and Sexton found "the change to the organizational culture is not complete... keeping in mind Kotter's lessons about how changes reverse when not grounded effectively in the culture, the StAR team appears to be on a good trajectory for making the strategic plan a living document relevant to the work of individuals across the organization" (Boff and Cardwell, 2020 p. 40).

Wesleyan University, a small residential liberal arts college in Middletown, Connecticut, entered the strategic planning process from the ground up. Wesleyan truly had to shift their entire culture in an incredibly short amount of time. Klare and Behney related "despite Kotter's framework, bringing about change can be difficult to institute within a precise and logically laid-out model. Humans are complex creatures, and that complexity is evidenced daily as an organization evolves and confronts both planned and unexpected changes" (Boff and Cardwell, 2020 p. 51).

In each section, after the final case study, Boff and Cardwell provide an excellent analysis chapter that discusses each case study through the lens of Kotter's eight step framework. Each analysis chapter provides an exhaustive review of the cases and also provides an excellent list of tips. One of the Journal of New Librarianship, 5(2020) pp. 188-194 
main takeaways I received from this section is the fact that change can be assessed even when it is not fully recognized or complete. Further, change can result, even when failures are first reported.

\section{Part 2. Reorganization}

Reorganization, whether of the physical space, or of services offered by departments, can be tricky to equitably negotiate. In this section, we are presented with case studies from Miami $(\mathrm{OH})$ University, UCLA, the University of Texas-Arlington, and Western Michigan University. Reorganization in these case studies can be viewed through the lens of change for the betterment of public services. Miami University Libraries, as previously mentioned, undertook the strategic planning process. Felix, et. al discussed the aspect of librarianship many of us need to be mindful of-perfectionism. It was established that through reforms and a pivot of thinking, that staffers discovered that they had the autonomy to try things and fail rather than being universally perfect (Boff and Cardwell, 2020 p. 69). For those education majors in the crowd, think of this as a growth mindset. The authors further establish that "fundamentally, in order for a change project to stick, an organization needs to feel discomfort with the status quo. Otherwise, models and methodologies are useless against a fixed mind-set" (Boff and Cardwell, 2020 p. 72). With a growth mindset, organizational change can flourish.

UCLA sought to reorganize and bring all public facing library services under the supervision of one associate university librarian (AUL). User Experience was at the forefront of this change process. This reorganization included dramatically different roles of faculty and staff members. The authors did not initially focus on this change through Kotter's framework but assessed change through this framework after the fact. UCLA has empowered their workers to lead change and develop new skill sets. Further, they establish that “...State 8 is not an anchor. Instead, it is a Launchpad for revisiting multiple stages of the organizational change process as UE works toward the goal of creating an 
innovative and collaborative culture" (Boff and Cardwell, 2020 p. 84). This case study further emphasizes the importance of a growth mindset.

Focusing on staff organization, the case studies of the University of Texas-Arlington and Western Michigan University, the overarching themes focused on library staff and faculty members getting outside of their comfort zones. In the case of UTA, emphasis was placed on being a "perpetual beta," which involves inferring that the only constant is change (Boff and Cardwell, 2020 p. 93). Multiple retirements at WMU drove the decision to reorganize the structure of the library from fourteen departments to streamlined divisions of labor in three main areas. The authors outlined that "the Kotter model reminds leaders that change requires continual care and monitoring if it is going to truly anchor itself within the organization" (Boff and Cardwell, 2020 p. 108).

\section{Part 3. Culture Change}

Presented in this section are case studies from Florida State University's STEM Libraries, Northern Arizona University, Rice University, and the University of Manitoba. Culture change is often difficult to quickly enact and quantify. Each case study presented an effective model of culture change focused on service to the public. Whether the institution wanted to become more proactive to user needs (FSU STEM Libraries), create a more user-friendly website (NAU), train faculty and staff members in excellent customer service strategies (Rice), or felt pressured to change a number of services from inperson to online delivery methods (UoM) each rapidly changed their culture and were able to assess the culture change through the steps of Kotter's framework.

Based on my work experience and personal history, Northern Arizona University's case study was especially intriguing. For the past two years, I have participated on a committee to assist in the redesign GALILEO (Georgia Library Learning Online), Georgia's Virtual Library. This work involved a process much like that of Northern Arizona University, especially the development of user personas, 
which both teams thought of as a generated short-term win. See and Childrey (2020) establish that "using the design-thinking approach, the UX groups empathized with end users by conducting user testing to define problems" (Boff and Cardwell, 2020 p. 142). Our project similarly did not employ the Kotter model, but both could be evaluated through this model as an afterthought. See and Childrey stated "although the Kotter model was not intentionally used in the construction of the initiative and the development of the process, in retrospect, many of the eight stages outlined in his book were put into practice and, as a result, have successfully changed the paradigm of program and service development for Cline Library" (Boff and Cardwell, 2020 p. 142-143). It should be established and understood that in most change situations, Kotter's model will not occur in an orderly, linear manner.

\section{Part 4. New Roles}

New roles in any area are often nerve-wracking. Changing roles in the library world is no exception. Covered in this section are case studies from Earlham College, the Universities of Florida and Maryland, and West Virginia University. Creative thinking about various ways to serve students with current library faculty and staff were discussed in this section. Earlham College developed their LIFT (Library Immersion Fellows Teams) as an effort to improve retention. Smathers Library at the University of Florida sought to implement a more robust Library Science internship program for graduate students. The University of Maryland revamped their library liaison program. West Virginia University's Libraries experienced a sense of urgency to provide services to student veterans. Viewed through the lens of these case studies reassigned roles and services provided dynamic ways of engaging students through emergence from typically siloed roles.

Of note in this section is the University of Maryland's reevaluation of their library liaison program through adoption of a framework of core competencies. While UoM did not initially follow Kotter's framework, they determined that it was followed in the evolution of their liaison program (Boff 
and Cardwell, 2020 p. 204). This case study presented an effective means for library management to reevaluate liaison service delivery.

\section{Part 5. Technological Change}

Covered in the final section is the role of leading change specifically related to the implementation of various technologies in the library. Case studies from Stephen F. Austin State University, the University of Alabama at Birmingham, the University of Virginia, and Vanderbilt University round out the technological change portion of the text. This section covered a broad array of technologies such as Digital Commons (SFA), a website redesign (UAB), digital productions workflows (UVA) and revamping communication systems within a large academic library (Vanderbilt). While the Kotter framework of change might not have been an explicit part of each project, they are easily assessable utilizing this framework.

Vanderbilt's transition to an Open News and Information Systems is a perfect example of assessing change through Kotter's lens after the fact. Vanderbilt Libraries sent a daily digest email everyday that related various events in their community. After nine years, this daily digest email was not the most effective means of communication (Boff and Cardwell, 2020 p. 258). Byrd, Stringer-Hye, and Gambrell related that "the Kotter framework was not part of the original plan, but it is easy to see how such a method would have been helpful if it were employed from the outset" (Boff and Cardwell, 2020 p. 266). One of the key themes of this text is that while the Kotter framework might not have been employed from the outset, it is easy to assess gains and struggles through this framework after the fact.

While this text is billed for middle managers and Deans, this book provides an introductory framework for library workers to understand various change processes. Existing at the intersection of business theory and library science, this text imparts a hopeful message about leading change in the academic library. Dr. Boff and Dean Cardwell are both leaders in our field and this text ultimately will 
help workers conceptualize and realize change in the academic library-it is possible! Filled with exhaustive analysis and tips, this is a must read for any academic library seeking to enact change. 